\title{
La depresión femenina vista desde la subjetividad de las mujeres
}

\author{
Female depression viewed \\ from women's subjectivity
}

\author{
1 Instituto Nacional \\ de Psiquiatría Ramón \\ de la Fuente Muñiz, \\ México DF, México. \\ Correspondencia \\ María Asunción Lara \\ Calzada México- \\ Xochimilco 101, \\ Col. San Lorenzo Huipulco, \\ Delegación Tlalpan, C. P. \\ 14370, México DF, México. \\ laracan@imp.edu.mx
}

\begin{abstract}
The aim of the study was to explore the way in which depression in women is conceptualized, experienced, and given meaning from the perspective of the women themselves, based on a review of text material on the subject. The focus group technique was used to present the text, which deals with depression, its causes, and coping strategies. Twenty-seven women, divided into four groups, participated in the study. Analyses of the transcriptions of self-recordings led to the identification of four categories: the experience of depression, childhood experiences, the female social condition, and coping strategies. The majority mentioned having had bouts of depression in their lives, although they had not recognized them as such. They were aware of the role played by socialization of the female role and certain childhood events in the emergence of depression and used various strategies to cope with this. The women found similarities between the ways they perceived depression and the descriptions in the text, and shared their own experiences. Depression was reported as a central theme in their lives, and they were eager to talk about it.
\end{abstract}

Women; Depression; Focus Groups
María Asunción Lara 1 Maricarmen Acevedo 1 Shoshana Berenzon 1

\section{Introducción}

La depresión es el problema de salud mental más común, y por lo tanto más importante, en la población femenina. Los datos epidemiológicos coinciden en señalar una razón de 2:1 en la prevalencia de depresión entre mujeres y hombres 1. La prevalencia actual de depresión en México es de 4,1\% en las primeras y 1,6\% en los segundos 2 . De manera similar a lo que ocurre en muchos países, en México, la atención a los trastornos mentales es muy limitada y, en este caso, las mujeres cuentan con pocas opciones de atención. Entre ellas, las de menores recursos económicos son quienes menos acceso tienen a los servicios de salud mental. Con base en estos antecedentes consideramos que una medida de educación para la salud podría beneficiar a las mujeres con esta problemática.

Para este fin, se pensó en un material educativo que en su versión final se publicó como ¿Es Difícil ser Mujer? Una Guía sobre Depresión 3. Se diseñó en forma de caricaturas y con un lenguaje sencillo para que pudiera ser leído con facilidad por mujeres con poca escolaridad. Durante el proceso de desarrollo del material se incluyó, entre otras, una fase de evaluación, através de grupos focales, para ver en qué medida éste cumplía con los objetivos de sencillez, claridad y pertinencia. Las informantes fueron mujeres de sectores populares que son a quienes va dirigido el material. Los resul- 
tados sobre los aspectos formales, como claridad de conceptos, relevancia de las imágenes, tipografía, etc., han sido publicados con anterioridad 4 . En el presente trabajo se analiza la manera en que conceptualizan, viven y lo que significa la problemática depresiva para ellas.

El material educativo fue desarrollado considerando el enfoque de género sobre la psicopatología femenina. En términos generales este enfoque implica romper con el modelo hegemónico biologicista, para considerar el psiquismo femenino como la expresión de las contradicciones inherentes a la condición de género y no ligado exclusivamente a la condición biológica 5. Por otro lado, en la construcción social de la enfermedad, y en este caso de la depresión femenina, existe una relación bidireccional, en tanto que la experiencia estructura la forma en que ésta se expresa, a la vez que su expresión se encuentra determinada por la experiencia misma. Es por esto, que la integración de ambos componentes es la que permite la comprensión del fenómeno en análisis. La ciencia social interpretativa 6 enfatiza la forma en la que los sujetos atribuyen sentido a sus experiencias de salud, por lo que hacemos una interpretación subjetiva de los significados de las participantes; es decir, nos acercamos a la comprensión mediante la interpretación. Es así como el análisis de las participaciones de los grupos da luz y complementa las nociones hasta este momento "objetivas y científicas" desde las que se ha abordado el fenómeno de la depresión femenina.

\section{Método}

Para recopilar la información se realizaron una serie de grupos focales, los cuales son definidos como una discusión cuidadosamente diseñada para obtener las percepciones sobre una particular área de interés. Los grupos focales constituyen una técnica cualitativa de recolección de información basada en entrevistas colectivas y semiestructuradas realizadas a grupos homogéneos y reducidos (de 6 a 12 personas). Por medio de un grupo focal se busca que, con la guía de un moderador, los integrantes se expresen de manera libre y espontánea sobre una temática específica 7 .

La técnica de grupos focales proporciona una aproximación y discusión relativamente rápida y multidimensional, permite la interacción del grupo y estimula la generación de ideas de forma simultánea. Esta técnica se enmarca dentro de la investigación socio-cualitativa, entendida como proceso de producción de significados que apunta a la indagación e interpretación de fenómenos. Además, se caracteriza por trabajar con instrumentos de análisis que no buscan informar sobre la extensión de los fenómenos (cantidad de fenómenos), sino más bien interpretarlos en profundidad y detalle, para dar cuenta de comportamientos sociales y prácticas cotidianas ${ }^{8}$. Por todo lo anterior, resulta ser una técnica adecuada para recuperar la forma en que un grupo de mujeres vive, expresa y significa el fenómeno de la depresión.

\section{Población}

La selección de las participantes se realizó através de un muestreo intencional o de conveniencia 9 , determinado por los objetivos del estudio y buscando que cada uno de los grupos fuera lo más homogéneo posible. Así, los requisitos para formar parte fueron: pertenecer a un nivel socioeconómico bajo o medio bajo; con escolaridad básica mínima de primaria; la mitad de ellas dedicadas al hogar y la mitad con trabajo extradoméstico y con edades entre los 20 y 45 años. Se contó con la participación de 27 mujeres, las cuales conformaron 4 grupos focales, dos de mujeres dedicadas al hogar y dos con trabajo extradoméstico.

\section{Procedimiento}

Se llevaron acabo dos sesiones por grupo focal, con una duración de dos horas y media cada una. Al inicio de la primera sesión, la moderadora explicó a las integrantes que el objetivo de la reunión era presentarles la versión preliminar de un libro sobre depresión, que estaba dirigido a mujeres con características similares a las de ellas. Se les señaló que para conocer su opinión sobre el material educativo se iba a realizar la lectura de los diversos capítulos y al término de cada uno se harían una serie de preguntas relacionadas con los aspectos formales del mismo, como por ejemplo: ¿Alguna parte te parece ofensiva?, ¿Qué partes no se entienden?, ¿Qué otros aspectos se deberían incluir?, así como sobre la pertinencia de los aspectos teóricos: ¿Qué aspectos te interesaron más?, ¿Qué aspectos no te interesaron nada?. Las participantes abordaron éstas preguntas brevemente, simplemente por cubrir el requisito. La discusión grupal se centró en la des- 
cripción de las experiencias relacionadas con la depresión. Se dio una dinámica interesante en los grupos, de compartir testimonios, discusión, confrontación de puntos de vista, consensos y consejos.

Las sesiones fueron grabadas íntegramente en cintas de audio y transcritas posteriormente a papel. Tomando como punto de partida las temáticas abordadas en el material educativo, se elaboraron una serie de categorías para clasificar la información dada por las participantes a lo largo de las sesiones. La clasificación se basó en la técnica de "categorización de significados" propuesta por Kvale 10, la cual permite efectuar inferencias válidas a partir de un texto. Por medio de esta técnica, cada testimonio, es codificado en una serie de categorías mutuamente excluyentes, lo que permite estructurar las extensas y complejas narraciones en unidades de información que facilitan la comprensión de un determinado fenómeno, así como su ocurrencia a lo largo de la narración, además de facilitar la descripción de las características más importantes del contenido.

Para llegar a un consenso sobre las categorías más adecuadas, dos personas por separado codificaron el mismo material y posteriormente se compararon las categorizaciones obtenidas por cada una.

En cuanto a los aspectos éticos, se proporcionó amplia información verbal respecto a los objetivos del estudio para cumplir con el principio de consentimiento informado y la participación fue voluntaria. Se pidió autorización para grabar los testimonios, haciendo hincapié en la estricta confidencialidad de los datos.

\section{Resultados}

La media de edad de las 27 mujeres que participaron fue de 34 años: 11 amas de casa, 16 con trabajos de mesera, asistenta, costurera o secretaria; 19 casadas, 3 en unión libre, 4 solteras y 1 divorciada; con escolaridad entre primaria y estudios de secundaria o equivalentes y sólo 2 no tenían hijos.

El análisis de los testimonios grabados y su posterior codificación en categorías y subcategorías, constituyeron la base de datos del trabajo. Se construyeron 4 categorías principales conformadas por diferentes subcategorías, las cuales representan los diversos tópicos tratados en el material educativo (Tabla 1). La descripción de cada una de ellas se inicia con una definición de los temas identificados y, posteriormente, se ilustran con segmentos de las narraciones de las mujeres.

\section{La vivencia de la depresión}

En esta categoría se agruparon los aspectos relacionados con el reconocimiento de la depresión como un trastorno, con la manera en que las mujeres identifican y viven los síntomas, con los pensamientos negativos asociados a la misma y con las diversas formas en que se puede manifestar.

\section{- Reconocimiento de la depresión}

En el material educativo la depresión es descrita a partir de los criterios diagnósticos propuestos por el Diagnostic and Statistical Manual of Mental Disorders (DSM-IIIR) 11: ánimo deprimido, pérdida de interés, sentimientos de culpa, falta de concentración, fatiga, exceso o falta de apetito y problemas del sueño, entre otros. Ante este material como estímulo, la mayoría de las participantes señaló que había oído hablar de la depresión de manera coloquial pero no formal y casi todas reconocieron haberla padecido en diferentes grados, pero no la habían identificado como tal. Se menciona que la depresión se vive como un problema personal más que como una condición común a las mujeres: "hay veces que por lo mismo que estamos tan deprimidas que pensamos que nadie lo tiene más que nosotras". Sólo una mujer refirió haber padecido varios episodios de depresión severa por los que ha sido hospitalizada. Les gustó que el material hiciera evidente que la depresión no es sólo un pretexto para ocultar el mal humor de las mujeres, como muchas personas creen: "me decían: tú, por no querer hacer nada... nada más por hacerte la mártir”.

Les pareció importante que se dijera que también los hombres pueden deprimirse. "Luego [ellos] creen que por ser hombres a ellos no les pasa". Se dan cuenta, sin embargo, de las diferencias que existen entre hombres y mujeres en cuanto a la depresión: "yo siento que en la mujer es más factible la comprensión hacia ciertos problemas, la identificación a decir soy depresiva, a que el hombre lo reconozca en sí mismo". Piensan que lo que más les afecta a ellos es cuando "se sienten impotentes para cumplir [económicamente] con su casa”, pero ellos expresan estos sentimientos de manera diferente, no con llanto sino con violencia y alcoholismo.

\section{- Síntomas}

En cuanto a los síntomas de la depresión, la mayoría dice haber presentado alguno de ellos; el más frecuente es el problema con la comida, comen mucho o no tienen apetito; pero tam- 
bién insomnio, ganas de llorar, desesperación, impotencia, desesperanza o labilidad emocional: "sí, si vuela una mosquita ya tiene uno ganas de llorar..., porque como que no voló bien; luego no sabe uno ni por qué está llorando" Piensan que las ideas sobre el suicidio "son algo exagerado", que "no ha pasado por mi mente" o "es cuando ya tienes muchos problemas...".

\section{- Estilos de pensamiento}

La depresión es descrita en el material educativo como efecto de estilos de pensamiento que se caracterizan por exigencias demasiado elevadas, por la atención discriminada a eventos negativos, por la exageración de hechos sin mayor importancia, por la atribución de causas personales a hechos externos y por la falta de reconocimiento a logros personales 12 . Con relación a este aspecto, encuentran que, en efecto, son muy exigentes consigo mismas: "soy terca en mi casa, porque llega uno a su casa con poco tiempo, en las tardes que llega uno de trabajar, y quiere hacer todas las cosas... prefiero seguirle hasta las 10 [de la noche]". Se exigen que todo esté bien y, sobre todo, que no "se les acumule el trabajo". Han internalizado esta demanda excesiva ya que no hay ningún reconocimiento del exterior; en este sentido, ni los maridos las valoran: "ay, estoy con ella porque es una buena mujer" cuando lo que quieren decir es: "estoy con ella porque es una buena sirvienta [Risas]... luego cuando ven otra más joven y más arregladita se van detrás de ella; no les importa que tengan una sirvienta excelente en su casa [Risas], los lava y los plancha para que otras lo bailen, ¿no?”. Este último comentario da cuenta de que se percatan del sinsentido de su propio comportamiento, pero aún así no pueden dejar de hacerlo.

En cuanto a las posibilidades de diversión, perciben que existen diferencias entre los hombres y las mujeres; en este sentido plantean que la sociedad permite a los hombres recreación como el fútbol, béisbol y demás deportes, mientras que a las mujeres, la misma sociedad les niega esta posibilidad de diversión. Asimismo, reconocen que dedican poco tiempo a sus cosas y a divertirse por el exceso de trabajo y la falta de dinero, pero también debido al estado de ánimo, lo que habla de la presencia de depresión: "pero yo luego me he puesto a pensar, no es tanto el dinero, porque yo puedo agarrar y llevar a mis hijas nada más a donde hay arbolitos y ahí no se gasta".
Tabla 1

Categorías de análisis.

\begin{tabular}{ll}
\hline Categoría principal & Subcategorías \\
\hline Vivencia de la depresión & $\begin{array}{l}\text { 1. Reconocimiento de la depresión } \\
\text { como enfermedad }\end{array}$ \\
2. Síntomas \\
3. Estilos de pensamiento \\
4. Formas de expresarla \\
Historia infantil \\
1. Pérdida temprana de figuras importantes \\
2. Falta de atención de los padres \\
3. Abandono o carencia de una relación \\
cercana \\
4. Expectativas y demandas elevadas \\
de los padres \\
5. Asumir fuertes responsabilidades \\
1. Socialización del rol femenino \\
2. Adolescencia \\
3. Sexualidad \\
4. Relación de pareja \\
5. Maternidad \\
6. Menstruación, depresión post-parto \\
y menopausia \\
7. Trabajo doméstico y extradoméstico \\
8. Alcoholismo y violencia \\
1. Qué hacer \\
2. A dónde ir \\
\hline
\end{tabular}

\section{- Formas en que se manifiesta la depresión}

Para algunas queda claro que la depresión se puede expresar de distintas maneras: "a veces la tristeza la refleja uno como enojada; en realidad no está enojada, está triste, pero no halla uno cómo manifestarlo". No encuentran de qué manera canalizar estos sentimientos que no sea "desquitándose" con los hijos/as: "me deprimo muchísimo, me pongo de malas, de nervios. No sé... hay veces que siento que me estalla la cabeza. A mis niños, por decir algo, a veces les pego, por lo mismo de que estoy deprimida. Esta manera de comportarse les genera muchas culpas".

\section{La historia infantil}

En relación con el desarrollo temprano, el material educativo se basa en varias teorías psicológicas que explican la relación entre experiencias en la niñez y la aparición de depresión en la edad adulta 13,14. Entre las experiencias relatadas por las mujeres destacan: la pérdida temprana de figuras importantes (en primer lugar 
la madre) por muerte, enfermedad o separación; poca atención de los padres, ser ignorada o ser hecha sentir un estorbo; la carencia de una relación cercana, las altas expectativas por parte de los padres y el asumir grandes responsabilidades desde edades muy tempranas.

Se dan cuenta de que efectivamente las experiencias tempranas tienen que ver con su conducta actual: "sí, también influyen nuestros padres; cómo nos educan o cómo los vemos que tienen sus relaciones". A la vez se percatan de la influencia que tiene la personalidad como un catalizador de los eventos ambientales: "yo pienso que depende de la persona, porque [hay personas que] llevan una vida infantil muy triste y no les llega a afectar y hay gentes que les afecta cualquier detalle, ¿no?”. La pérdida temprana de la madre se presentó en tres casos, que pudieran considerarse como duelos no elaborados: "mi mamá murió muy joven... piensas que todo se acaba. Ya después recuerdas, a veces con tristeza, y piensas y te deprimes".

La falta de atención la identifican como una de sus fuentes de depresión: "la falta de atención hace sentir también deprimido; de que reflexiona uno y dice: no me escuchan, no tengo quién me escuche". También recuerdan maltrato y el que se les exija responsabilidades poco adecuadas para su edad: "[mi abuelita] me ponía a hacer cosas que no estaban para mi edad, $y$ [me decía]: no sirves para nada. Una niña de 6, 7 años, ¿ponerse a sembrar?, cosas no para su edad".

\section{Condición social de la mujer}

En esta sección se resumen una serie de datos respecto a los factores de género que ponen a la mujer en un alto riesgo de depresión $5,15,16,17$, 18. En primer lugar, se encuentra la socialización del rol femenino (a ser pasivas, abnegadas, sumisas, consideradas como menos valiosas y con demandas de mayor responsabilidad; la valorización de la mujer en tanto tiene un hombre, el poco énfasis en la educación, etc.). En segundo lugar, se revisan las vivencias tradicionales de ciertos roles (adolescente, sexualidad, madre, esposa, ama de casa, trabajadora) como factores depresógenos; y, por último, se mencionan algunos aspectos reproductivos, alcoholismo y violencia en la familia.

\section{- Socialización del rol femenino}

La mayoría coincidió con que a las mujeres se las educa " a ser sumisas", a "no grites, no te enojes, no te pelees" y "a no valorarnos"; se les "mete muy chicas a las responsabilidades" y se les dice que si "se casa es para la casa, para los hi- jos, es para el marido" y "es la que lleva toda la carga, todas las presiones". Pero también perciben cambios: "pero antes yo pienso que era más, porque, por ejemplo mi abuela, no tenía educación". Por lo mismo, dicen que ya no educan a sus hijas "para servirle a los hombres", y tratan de "darles una educación un poquito más elevada, para que se puedan defender ellas mismas". No obstante, piensan que ahora hay mujeres que "exageran", sobre todo algunas adolescentes, y ellas se preocupan por no llegar a esos extremos. Aunque no quieren que sus hijas sean unas sumisas, tampoco quieren "que saquen las uñas luego, luego”. ¿En dónde está el punto medio?, se preguntan, porque pueden irse a los extremos.

Hablan de la importancia de que la mujer se prepare: "si nuestros padres no nos permitieron trabajar, abrirnos la vida, entonces, si nos llegamos a casar y fracasamos en el matrimonio, nos sentimos que se acabó el mundo entero y si no sabe uno hacer nada, le da a uno miedo caminar".

Respecto a que los hombres son más valorados desde que nacen, muchas piensan que efectivamente vivieron experiencias en su infancia en las que el papá quisiera tener un hijo varón, que se les diera un lugar de más importancia a los hombres.

\section{- Adolescencia}

A esta edad consideran que con frecuencia las muchachas, por sentirse feas o por salirse de la casa, "se van con un muchacho". La falta de información influye en que se lleguen a embarazar y mencionan la falta de aceptación que sienten cuando son madres solteras: "yo sí sentí que ya no me iba a encontrar a alguien", y se percatan de la desventaja en que está la mujer si se embaraza sin el apoyo de la pareja: "como mujer, siempre es la primera que pierde", además de que después puede arruinar su vida si se ve forzada a casarse.

Sobre las mujeres que no se casan y no tienen hijos, comentan: "es lo primero que la gente o las mujeres pensamos. A lo mejor no es feliz porque no tiene hijos; está amargada". Dicen que la sociedad las presiona: "si no tienes marido por lo menos ten un hijo. Entonces como que a veces acaban decidiendo, para que no hablen mal de ellas".

\section{- Sexualidad}

En uno de los grupos no se hicieron comentarios sobre la sexualidad, lo que probablemente muestre las dificultades que prevalecen para 
hablar abiertamente sobre el tema. Varias coinciden con que se habla mucho de sexo pero sólo para "despertar la morbosidad" y, a veces, sólo se produce desinformación.

En general, creen que sigue habiendo una doble moral sexual, "pues el hombre puede darse sus vueltas por donde quiera, pero la mujer cuidado y tenga un resbalón, porque está mal", pero a la vez, admiten que la mujer va cambiando, forzada por la situación tan opresiva: "de que uno mismo como cuando te estás ahogando, pues sacas la cabeza y ¿qué onda? porque, oye, si los dos trabajamos, los dos aportamos, pues hay que echarle filo los dos juntos".

Hay mujeres que muestran apertura ante la sexualidad: "a mí no me da vergüenza, yo pido de todo al derecho y al revés" y otras que sienten vergüenza de expresar sus deseos a la pareja o de "ver" revistas (pornográficas), aunque suponen que ellos son las que están mal. Algunos maridos se sienten "amenazados y enojados" si ellas se informan de temas sexuales.

Varias hablan de la infidelidad como una situación que lleva a la depresión y una mujer llora mientras relata el engaño de su marido hace tres años: "él quiso ser igual que antes, dije, ay, ya no, y él me pidió perdón. Pues sí lo perdoné, pero no se me quita eso de aquí. Eso no se lo deseo a nadie, es horrible".

\section{- Relación de pareja}

La mala relación con la pareja es una de las fuentes más importantes de depresión: "ahí sí cuando hay problemas [con la pareja], y que no le busca uno una solución, lo llevan a una depresión tremenda". Entre las situaciones que llevan a las mujeres a deprimirse, está la dependencia de la mujer hacia el hombre: "me han tocado comentarios también de que la mujer no puede estar sin el hombre; o sea, siente que si se separa se le viene el mundo encima", y piensan que eso las hace vulnerables.

Otra situación que les causa malestar es el control de los hombres: "y peor cuando, voy a ir a tomar un café, voy a ir a tal parte. ¿Me estás pidiendo permiso o me estás avisando? Yo te estoy avisando. [Risas]", "sí, es cierto ¿cómo tenemos que pedirle permiso al marido si se supone que son marido y mujer? Ya no se usa". O cuando ellos quieren decidir todo y no dejan que la mujer decida: "y no está bien... porque eso también hace que la mujer se deprima más y sobre todo porque no la hacen valer como mujer". Las exigencias del marido sin que ellos cumplan con sus responsabilidades, también las deprime. Sin embargo, aguantan estas situaciones, por lo general, por los hijos, aunque reflexio- nan: "sí, uno lo hace todo por sus hijos. Pero ¿a poco te vas a arruinar la vida ahí nomás? Los hijos crecen y se van y te dejan".

Pero ¿qué pasa cuando los hombres sí las apoyan? Fue común que dieran ejemplos de hombres, ya fuera marido, hermanos o papá, que ayudan en las labores de la casa, "en todo: barrer, lavar, cocinar, limpiar" y que las gentes de fuera los tachara de mandilones. Muchos, para evitar esto, les piden que no los hagan hacer estas tareas cuando hay otras personas. Aún más, una mujer cuenta que su esposo ha sido su mejor apoyo en su depresión.

\section{- Maternidad}

La preocupación sobre los hijos e hijas fue expresada en muchas ocasiones: cómo educarlos, que vayan bien en la escuela, que no tengan los mismos problemas que ellas y cómo hablarles sobre la sexualidad. Se percatan de la gran responsabilidad que se les delega: "nosotras debemos de dar razón de todo lo que pasa o sea de la escuela, de ellos mismos. Así, de todo", principalmente cuando los esposos no las apoyan, comentan: "uno quiere lo mejor, ¿verdad? Porque los padres agarran y se van a trabajary una como madre se queda con los problemas de todos los hijos". Es común que las culpen de los problemas de los hijos: "por decir: sale que no es buen estudiante o es drogadicto. Sí se siente culpa, porque uno mismo juzga a los padres de otros".

Las relaciones con hijos e hijas adolescentes son vividas como fuente de depresión ya que tienen dificultades para que las obedezcan y retan su autoridad. Las mujeres también expresan una gran preocupación por "cuidar" a sus hijas adolescentes, sobre todo para que no inicien su vida sexual a edades tempranas y así evitar las posibilidades de embarazos. Otras mujeres piensan que cuando los hijos llegan a determinada edad "desequilibran el matrimonio, porque vienen las desavenencias [en la manera de educarlos]".

\section{- Menstruación, depresión post-parto y menopausia}

La ausencia de información sobre la menstruación cuando ésta se inició es común, así como la mala información. Una mujer cuenta que cuando tuvo su primera regla su mamá le dijo que no se debía dejar tocar por los hombres, y lloraba mucho si su hermano la tocaba al saludarla. Afirman que durante la menstruación se sienten desganadas, de mal humor o sufren angustia si son irregulares. 
Cuatro de ellas cuentan experiencias de depresión post-parto. Un testimonio: “yo, más que nada, todo me daba ganas de llorar. Yo me acuerdo que cuando nació mi niña me la enseñó el doctor y me la pasé llorando no sé cuánto tiempo. Me decían todos, ¿por qué lloras? ¿Te duele algo? No me lo podía explicar". Otras relacionan la depresión post-parto con haber estado solas, sin su pareja, durante el parto o con problemas familiares después de dar a luz. Ninguna tuvo información pertinente.

Ninguna de las mujeres ha llegado a la menopausia, pero han oído hablar de ella: "se siente deprimida y lo manifiestan más malhumoradas y lo asustan a uno [Risas]", "y también sucede más cuando la gente se ha sentido siempre guapa y cuando hay gente muy vanidosa; se va a sentir fea". La menopausia tiene una connotación peyorativa: cuando te deprimes, te gritan "estás menopáusica".

\section{- Trabajo doméstico y extradoméstico}

Las amas de casa piensan que si no se tienen carencias económicas o si se es "un poco independiente de los hijos" se puede disfrutar estar en la casa; justifican el trabajo fuera del hogar sólo si hay necesidad. Ven ventajas en estar en la casa, porque la disfrutan y disfrutan a los hijos, pero también en trabajar fuera: "saliéndose a trabajar, como que dejan un poquito de tensiones".

Las mujeres trabajadoras se sienten afectadas por la manera en que se las juzga: "muchas veces critican a uno sin saber cómo está realmente la cosa". También las critican de lo que les sucede a sus hijos "si se cae el niño o le pasa algo: es por tu culpa, andas trabajando". Pero tratan de no dejarse culpabilizar viendo lo bueno: "[mi hijo] va feliz, nunca me llora, entra a la guardería y ni me pela" " "muchas veces son mejores las guarderías que con la abuelita, que con la tía, porque ahí les enseñan cosas". Se sienten muy mal cuando dejan a los hijos/as en la guardería y se "quedan llorando" o cuando "están muy chiquitos", pero tratan de animarse diciendo: "ojos que no ven, corazón que no siente [Risas]”. Consideran que hay mujeres que están en su casa porque no tienen otra alternativa: "no pueden salir a trabajar porque no saben" y en ese caso "deberían estar a gusto". Aunque algunas se percatan de que el trabajo doméstico "es aburrido, no acaba uno, no facilita conocer a personas que por lo menos saben más" y puede llevar a la depresión.

\section{- Alcoholismo y violencia}

Pese a la alta frecuencia con que se presentan el alcoholismo y la violencia doméstica en los hogares mexicanos, hay muy pocas menciones a este respecto. Esto puede deberse a dificultades para hablar de estas situaciones por ser vistas como vergonzosas o como una debilidad de ellas.

Dos mujeres hacen mención al alcoholismo: "en problemas de alcoholismo yo me aventaba unos rounds. Digo, aparte de que aguanta uno el maltrato verbal, le dicen a uno hasta lo que no, te quieren dar un golpe, pero borracho, me lo sueno" y otra menciona que su esposo alcohólico les pegaba a sus hijos, hasta que ella se hartó y no le dejó que les pegara más.

Relacionan la violencia con la manera de educarlas: “donde más les pegan, ahí están las mujeres. Uno no comprende, pero ahí están. Las tratan mal, les pegan, las corren y ahí están. Éstas son las que son educadas así, de si que ahí está el marido, aunque te pegue y te haga aquello, pero tú ahí. Opinan que se aguantan por "miedo de que el hombre tome más represalias" o por miedo al rechazo social: "la pena de qué va a decir la cuadra entera si me salgo corrien$d o$ ". Piensan que si desde un principio no se dejan, les va bien: "sólo una vez me quiso pegar, pero yo no me dejé. Desde entonces jamás. Ha de haber dicho: no, aquí no [Risas]".

\section{Estrategias de enfrentamiento}

La primera subcategoría incluye información sobre las actividades y estrategias que realizan las mujeres para sobrellevar o mejorar sus estados depresivos. La segunda se refiere a su percepción de los servicios de salud y su eficacia en el tratamiento de problemas emocionales como la depresión.

\section{- Qué hacer}

En el material educativo se presentan una serie de sugerencias de autoayuda que incluyen estrategias de reestructuración cognitiva, catarsis y cambios en creencias y comportamientos 19,20. De estas sugerencias las participantes mencionaron como importantes: "reconocer cualidades y errores", "dejar de ser mujeres sufridas" y "escribir sobre los problemas, porque te desahogas y olvidas rencores".

La sugerencia de platicar los problemas con las amigas, la ven con ambivalencia. Por un lado, reconocen lo importante que son las amigas pero, por el otro, hay un gran temor a que las critiquen. Se mencionaron diversas estrategias que usan cuando se sienten deprimidas. Se menciona la importancia de dar salida a los sentimientos: "a veces es preferible, cuando sientes todo eso, gritar, llorar y desahogarse, y enton- 
ces ya descansas". Pero lo importante de desahogarte, dice otra mujer, es "tener a alguien que aguante todo y que no diga nada...". Otras usan estrategias de reflexión, distracción, platicar con alguien, salir de compras o ir regularmente a salones de baile. También intentan pensar de manera positiva: "nada gano con preocuparme..., si no se puede solucionar para qué te preocupas; si tiene solución para qué te preocupas", "si he salido de otros problemas, debo de salir". Hay constantes referencias a "intentar salir adelante" con fuerza de voluntad, con "el querer es poder".

Tres de ellas mencionan que suelen escribir cuando se sienten mal y les ha funcionado muy bien: " a mi me ha pasado cuando estoy enojada que me he puesto a escribir...lo leo y luego... qué si estaba bien, qué si estaba equivocada. Ya no es tanto el problema". Buscan hacerse responsables de sus problemas y no echarle la culpa a otros.

Como conclusión, comentan que lo que tienen que hacer es: "qué uno se ponga a pensar en uno y que haga una evaluación de sí mismo, qué es lo que está fallando y qué lo pone a uno así. Haz un alto y ponte a ver cuánto vales y corriges. Todos tenemos fallas desde pequeños, que salen a relucir a veces cuando ya somos adultos con hijos; todos tenemos problemas pero no los voy a dejar ahí sino los vamos a tratar de solucionar".

\section{- A dónde ir: los servicios de salud}

Para la mayoría, tengan seguridad social o no, son desconocidas las instituciones o los trámites para contactar un especialista en caso de problemas emocionales. Tampoco conocen organizaciones no gubernamentales de ayuda para las mujeres. Respecto a las instituciones públicas hay distintos puntos de vista en cuanto a la eficiencia de sus servicios, dependiendo de sus experiencias. Se quejan de malos modos, lo que las lleva a sentirse deprimidas y sin valor. También se quejan de demoras para obtener una cita, con resultados no siempre positivos: "para al final salir con que son nervios; es cuestión de que se controle. Váyase, tómese un tesito...". Por el contrario, alguien afirma que: "sí es bueno acudir a pedir ayuda y sí surte efecto".

Algo que las disuade de ir a instituciones especializadas es el estigma de los problemas mentales: "lo tratan a uno de a loco". Por eso creen que es mejor contárselo a una amiga o mejor a sus familiares, ya que afirman "¿quién va a tener más interés en sacarte a ti adelante?" Sin embargo, también ven desventajas en acudir con un familiar debido a que "a veces no sa- ben cómo ayudarte. Aunque te quieran mucho, a veces te pueden lastimar".

Una mujer ha sido internada en el pasado debido a depresión y, aunque siente que la ayudaron, menciona los problemas de las instituciones psiquiátricas: "lo malo estaba en ver a los demás enfermos; me daba miedo".

Para una de ellas el factor más importante para que la ayuda que se recibe tenga buenos resultados es la actitud de quién la solicita: "primero que nada, la voluntad de la persona y aceptar una información y ayuda”. Otra resalta la importancia de terminar con el estigma hacia los problemas mentales para verlos como cualquier problema de salud.

\section{Discusión y conclusiones}

Los testimonios recopilados en este trabajo ponen de manifiesto el gran interés de las mujeres por el tema de la depresión y por los aspectos que llevan a ésta. Ninguna había oído hablar de manera formal de este trastorno, pero todas reconocen haberlo presentado, en algún nivel, alguna vez en su vida. Algunos de los síntomas de la depresión que identificaron como más frecuentes son los trastornos relacionados a la alimentación y al sueño; llanto, desesperación, impotencia y desesperanza. Reportaron asimismo la presencia de un estilo negativo de pensamiento ligado a la depresión. Como se sabe, los sentimientos de desesperación, impotencia y desesperanza son frecuentemente reportados por personas en estado de pobreza 21 , mientras que, los estilos de pensamiento característicos de la depresión parecen fortalecerse en el proceso de socialización del papel femenino, en tanto que son sujeto de demandas excesivas, se les delegan grandes responsabilidades, se les inculca vivir de y para otros, etc. 5 . Por lo anterior, se observa que el proceso de socialización del papel femenino y la condición de pobreza de las mujeres las pone en un estado de gran vulnerabilidad de depresión. En menor número llegan a presentar un cuadro de depresión severa, pero para la gran mayoría cumplir con las demandas de su papel las lleva a síntomas de depresión, factor que puede contribuir a explicar la mayor frecuencia de depresión en las mujeres.

Casi todas reconocen la relación entre experiencias de la infancia y comportamiento adulto. Algunas relatan buenas relaciones con sus padres, pero un mayor número ha perdido, a edad temprana, a alguno de ellos; ha padecido de falta de atención, malos tratos, abandonos o alcoholismo del padre, o ha vivido una 
infancia con vergüenza y confusión. Estos aspectos hacen vulnerables a las mujeres de futura depresión. Las mujeres han asumido grandes responsabilidades y trabajo excesivos como parte natural de su papel, por lo cual les parece extraño que estas situaciones puedan significar algún problema en su desarrollo psicológico, cuando se inician a edad temprana.

Se percatan de los distintos procesos de socialización para hombres y mujeres con base en la supremacía masculina, pero a la vez perciben cambios hacia mayores oportunidades para las mujeres. Tienen, sin embargo, temor de caer en extremos, esto es volverse muy liberadas, así como, confusión respecto a cuál es ahora el deber ser respecto al comportamiento femenino.

La adolescencia es un periodo crucial respecto a su futuro debido a las limitadas opciones de educación y empleo, por temores a no consolidar una relación de pareja y no casarse y por la posibilidad de un embarazo sin el apoyo de la pareja. Más tarde, la desigualdad de poder en la pareja y la preponderancia que las mujeres le dan a los afectos lleva a que la relación de pareja sea un factor importante de riesgo de depresión.

La etapa de la maternidad que se reporta como la más difícil y como una fuente importante de tensión es cuando se enfrentan a los y las hijas adolescentes. Se muestran "perdidas" respecto a cómo enfrentar los conflictos característicos de ese periodo. A veces se muestran muy exigentes, otras muy permisivas y otras descargan su agresión sobre sus hijas y les niegan, de muchas maneras, la posibilidad de un mejor futuro. Temen que la sociedad les reproche el posible fracaso de sus hijos, pero sobre todo, de sus hijas.

No fue poco frecuente la experiencia de depresión post-parto, ante la cual ninguna tuvo información previa sobre ésta, ni la recibió durante el periodo en que duró. Este hecho es una llamada de atención sobre la necesidad de proporcionar mayor información a las mujeres sobre este padecimiento, pero también de la responsabilidad del personal médico ante este problema.

Es de llamar la atención que, siendo la violencia intrafamiliar y el alcoholismo fenómenos con tan alta incidencia, ninguna hiciera alguna referencia personal respecto a la primera y muy pocas mencionaran el segundo. Es posible que así sea, pero también es posible, como lo muestra la literatura 22 , y como ellas mismas refieren, que estos eventos no sean reportados por temor a la sanción social.

Es frecuente que usen diversas estrategias para enfrentar el malestar emocional, como dar salida a los sentimientos, pensar de manera positiva o llevar a cabo acciones concretas. Sin embargo, una estrategia común fue la ironía y el sentido del humor, los cuales estuvieron presentes durante las sesiones, pese a lo doloroso o difícil del material a tratar. Aun así, las estrategias no son suficientes y, al no haber otras alternativas porque la sociedad ha negado a las mujeres la posibilidad de expresar abiertamente sus frustraciones y porque mantiene sobre ellas demandas imposibles de cumplir, con frecuencia reportan "desquitarse" con los hijos/as. Esto se traduce en culpa y ésta, a su vez, en mayor depresión y enojo. Este es un aspecto de gran importancia para entender y atender la depresión femenina, ya que si bien es cierto que los hijos de mujeres que padecen depresión presentan con frecuencia problemas emocionales 23 , la solución tiene que darse a través de proporcionar atención a estas mujeres evitando hacer mayores demandas y depositar más culpas sobre ellas.

Que no supieran a dónde acudir en caso de necesitar ayuda especializada concuerda con la percepción que tiene la población general 24 . Pocas han tenido experiencias positivas con los servicios de salud mental - no utilizados para ellas sino para de sus hijos/as. Una gran mayoría tiene actitudes de desconfianza, temor o vergüenza en cuanto a estos, por el estigma que aun conllevan los trastornos emocionales: ser considerada loca. También temen que sus problemas sean minimizados o que sean culpabilizadas por ellos, como también se ha informado en otros trabajos 24 .

Los acertados conocimientos que las mujeres de este estudio mostraron sobre la depresión - aunque no la definieran como tal - y las características y condiciones en las que se da nos llevan a concluir sobre la importancia de tomar en cuenta el caudal de conocimientos que tiene la población, con el fin de propiciar un diálogo con ésta, cuando se trata de establecer programas de atención y prevención para la misma. Su visión tiene que ser, necesariamente, parte de una visión más integral sobre la depresión. 


\section{Resumen}

El objetivo del trabajo fue explorar la manera en que la depresión femenina es conceptualizada, vivida y significada por las propias mujeres, a partir de la revisión de un material sobre el tema. Se utilizó la técnica de grupos focales para la presentación del texto, el cual versa sobre la depresión, sus causas y estrategias para enfrentarla. Participaron veintiséis mujeres divididas en cuatro grupos. El análisis de las transcripciones de audiograbaciones llevó a identificar cuatro categorías: vivencia de la depresión, historia infantil, condición social de la mujer y estrategias de enfrentamiento. La mayoría mencionó haber padecido episodios de depresión en su vida aunque no los había reconocido como tales. Se percatan de la influencia que tiene la socialización del papel femenino y los acontecimientos de la infancia en la depresión y utilizan diversas estrategias para enfrentarla. Las mujeres encontraron similitudes en sus vivencias a las descritas en el material y a partir de éste relataron sus propias experiencias de depresión. La depresión es un tema central en sus vidas y están ávidas de hablar de ésta.

Mujeres; Depresión; Grupos Focales

\section{Colaboradores}

M. A. Lara participó del diseño del material sobre depresión, del desarrollo de la metodología, del análisis de resultados y de la preparación de artículo, y fue conductora de la mitad de los grupos focales. M. Acevedo participó en todas las fases del estudio y condujo la mitad de los grupos focales. S. Berenzon participó en el diseño del marco conceptual para la elaboración del material, en el análisis de los datos y en la preparación del artículo.

\section{Referencias}

1. World Health Organization. Gender differences in the epidemiology of affective disorders and schizophrenia. Geneva: World Health Organization; 1997.

2. Berenzon S, Medina-Mora ME, López EK, González J. Prevalencia de trastornos mentales y variables asociadas en cuatro comunidades del sur de la ciudad de México. Revista Mexicana de Psicología 1998; 15:177-85.

3. Lara MA, Acevedo M, Luna S, Weckmann C, Villarreal AL, Pego C. ¿Es difícil ser mujer? Una guía sobre depresión. México, DF: Editorial Pax; 1997.

4. Lara MA, Acevedo M, López EK. La investigación aplicada a la educación para la salud. El caso de la depresión en las mujeres. Psicología y Salud. Nueva Época 1998; 12:55-66.

5. Burin M, Moncarz E, Velázquez S. El malestar de las mujeres. La tranquilidad recetada. México, DF: Paidós; 1990

6. Weber M. Economía y sociedad. México, DF: FCE; 1981.

7. Krueger R. Focus groups. A practical guide for applied research. Thousand Oaks: Sage Publications; 1988.

8. Stewart DW, Shamdasani PN. Focus groups: theory and practice. London: Sage Publications; 1992. 
9. Patton M. Qualitative evaluation methods. Beverly Hills: Sage Publications; 1980.

10. Kvale S. Interviews: an introduction to qualitative research interviewing. London: Sage Publications; 1996.

11. American Psychiatric Association. Diagnostic and statistical manual of mental disorders. 3rd Ed. Washington, DC: American Psychiatric Association; 1980.

12. Wolman B, Stricker G. Depressive disorders. Facts, theories and treatment methods. New York: John Wiley and Sons; 1990.

13. Bowlby J. Attachment and loss. Vol. 3. Loss, sadness and depression. New York: Basic Books; 1980.

14. Brown G, Harris T. Social origins of depression: a study of psychiatric disorders in women. London: Tavistock; 1979.

15. Lagarde M. Cautiverios de las mujeres: madresposas, monjas, putas, presas y locas. México, DF: Universidad Nacional Autónoma de México; 1990.

16. Lara MA, Salgado de Snyder N. Mujer, pobreza y salud mental. In: Alatorre J, Careaga G, Jusidman C, Salles V, Talamante C, Townsend J, compiladores. Mujeres en la pobreza. México, DF: El Colegio de México y GIMPTRAP; 1994. p. 243-91.

17. Lara MA, Acevedo M, López EK, Fernández M. La salud emocional y las tensiones asociadas con los papeles de género en las madres que trabajan y en las que no trabajan. Salud Mental 1993; 16:13-23.
18. McGrath E, Keita G, Strickland B, Russo N. Women and depression. Risk factors and treatment issues. Washington, DC: American Psychological Association; 1990.

19. Juniper D. How to lift your depression. London: Open Books; 1977.

20. National Institute of Mental Health. Depression. What you need to know. Rockville: Public Health Service; 1994. (NIH Publication No. 94-3808).

21. Ortega S, Corzine J. Socioeconomic status and mental disorders. Res Community Ment Health 1990; 6:149-82.

22. Natera G, Mora J, Tiburcio M. El rol de las mujeres mexicanas frente al consumo de alcohol y drogas en la familia. Revista de Psicología Social y Personalidad 1997; 13:165-90.

23. Zoccolillo M, Cloninger C. Somatization disorder: psychological symptoms, social disability and diagnosis. Compr Psychiatry 1986; 27:65-73.

24. Lara MA, Medina-Mora ME, Salgado de Snyder VN, Acevedo M, Díaz-Pérez MJ, Villatoro J. Utilización de servicios para problemas de salud mental en población femenina: tres estudios. Salud Mental 1996; 19:42-9.

Recibido el 17/Feb/2003

Versión final presentada el 13/Oct/2003

Aprobado el 13/Ene/2000 